\title{
Research
}

\section{Collapse and Recovery in Sahelian Agro-pastoral Systems: Rethinking Trajectories of Change}

\author{
Laura Vang Rasmussen ${ }^{1}$ and Anette Reenberg ${ }^{1}$
}

\begin{abstract}
We discuss the adaptive cycle heuristic as a potential platform for describing the functioning and directions of change in Sahelian land use systems. Specifically, the aim is to go beyond the simplified narrative of a vicious circle of land degradation and land expansion prompted by population pressure and low rainfall and to develop conceptual means to account for system recovery and adaptation to exposures. We use a village study from northern Burkina Faso as an empirical point of departure. On the basis of information obtained from extensive interviews and surveys at the group and household level, the different phases of the adaptive cycle — exploitation (r), conservation $(\mathrm{K})$, release $(\Omega)$ and reorganization $(\alpha)$ - are characterized by indicators of "potential" and "connectedness". The main traits of an adaptive cycle trajectory are identified, yet deviations are also observed. It is, however, apparent that the traditional picture of a unidirectional process of land degradation and system collapse in Sahelian agro-pastoral systems is a simplification of more complex realities. The adaptive cycle heuristic provides insight into the possible importance of, for example, connectedness in terms of village groups. This may have implications for the policy discourse and may contribute to a more comprehensive understanding of trajectories of change in Sahelian systems.
\end{abstract}

Key Words: adaptive cycle; connectedness; potential; Sahel; social-ecological systems

\section{INTRODUCTION}

In recent research, the complexity of Sahelian land change processes has increasingly been recognized after decades of focus on the simplified narrative of a vicious circle of land degradation and land expansion prompted by population pressure and low rainfall. Statements like "Sahelian farmers are still in business" (Mortimore and Adams 2001) and "Farmers in the Sahel are moving beyond climate" (Nielsen and Reenberg 2010b) highlight that this prevailing notion of change as a unidirectional process may not conform well to reality (Mortimore and Turner 2005, Mortimore 2006). Contrary to much of the standard rhetoric concerning land degradation, Sahelian systems thus also seem to reveal traits of recovery by absorbing pressures and shocks. Such recognitions invite revisions to the basic understanding of dynamics and behavior of Sahelian systems. In particular, researchers need to adopt approaches that take the possibilities of system recovery into account.

Recently, new concepts, theories, and metaphors have been suggested to help understand transformations in complex social-ecological systems such as the Sahelian systems. Resilience theory (Gunderson and Folke 2005, Folke 2006, Kinzig et al. 2006, Walker et al. 2006b, Carpenter et al. 2009), which proposes five heuristics to describe patterns of change (adaptive cycles, resilience, panarchy, transformability, and adaptability), has been suggested as a means of capturing dynamics in complex social-ecological systems and as a useful framework since it accounts for system recovery and adaptation to exposures (Walker et al. 2006a).
We test the explanatory usefulness of resilience theory for a Sahelian social-ecological system. In more concrete terms, we apply the adaptive cycle as a diagnostic tool to explore the dynamics and trajectories of change in a village in northern Burkina Faso. We specifically explore the period since the droughts that caused significant famine and loss of livestock in the region in the early 1970s. By confronting the adaptive cycle with a Sahelian case area, we test whether, in fact, the heuristic adds value to understanding the functioning and directions of change in a village-scale system. Hence, our overall objective is to discuss the adaptive cycle as a potential contribution to developing a new framework of the dynamics in Sahelian systems that takes into account mechanisms of collapse and recovery as part of the change process.

\section{THE ADAPTIVE CYCLE AS A HEURISTIC APPROACH}

The adaptive cycle was developed by Holling (2001) on the basis of research into ecological systems. It proposes a basic notion of a cycle of exploitation, conservation, release, and reorganization (Fig. 1). The cycle has been described as moving slowly from exploitation $(r)$ to conservation $(K)$, maintaining the conservation stage for a prolonged period and then moving on to a collapse or release phase $(\Omega)$, which rapidly progresses to a phase of reorganization $(\alpha)$ before turning back to exploitation $(r)$ (Holling and Gunderson 2002). According to the theory, the system can then begin a new adaptive cycle or alternatively shift to a different regime, shown as the exit arrow in Fig. 1. Although the notion of an adaptive cycle at the outset was developed as a useful metaphor 
for describing change in ecological systems, it has since proven useful for analyzing how social-ecological systems and even social systems change through time (Abel et al. 2006).

Fig. 1. The adaptive cycle describes four phases of change along the connectedness ( $\mathrm{x}$ axis) and potential (y axis) dimensions. (Adapted from Gunderson and Holling [2002])

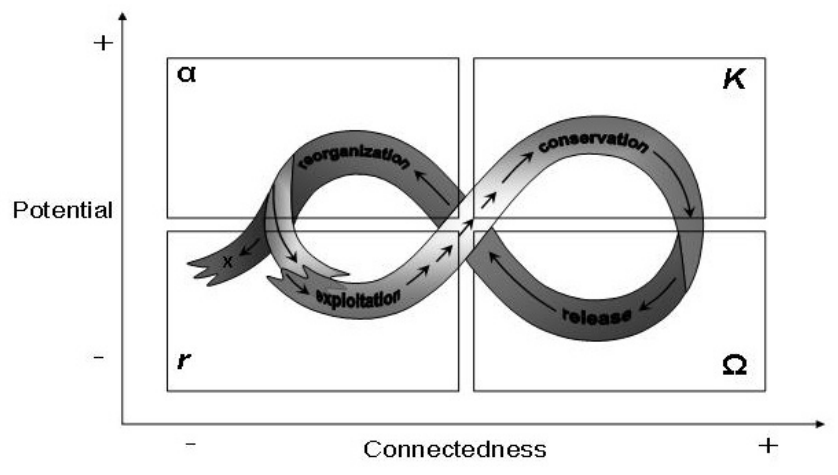

The adaptive cycle consists of three dimensions: the potential, the connectedness, and the resilience of the system. The resilience of the system expands and contracts throughout the cycle in relation to the two key properties: potential and connectedness. The potential "can be thought of, loosely, as the 'wealth' of a system" (Holling 2001:394), and thus the range of accumulated resources such as economic, social, and environmental capital that are available and accessible. The connectedness reflects "the internal controllability of a system; that is the degree of connectedness between internal controlling variables and processes, a measure that reflects the degree of flexibility or rigidity of such controls, such as their sensitivity or not to perturbations" (Holling 2001:394). According to the adaptive cycle heuristic, the degree of connectedness and the potential differ throughout the cycle. Hence, the heuristic suggests that the four phases can be distinguished on the basis of the relative levels of the two properties.

Since the adaptive cycle was initially proposed, the heuristic has been applied to a number of case studies that have examined changes in social-ecological systems (Alcorn et al. 2003, Seixas and Berkes 2003, Abel et al. 2006). These studies have used the adaptive cycle to analyze specific cycle phases. However, little has been written about case studies that describe and quantify the entire adaptive cycle, with a few notable exceptions. These include Allison and Hobbs (2004), who studied agricultural systems in Australia, and Beier et al. (2009), who analyzed changes in public land governance and forest management in Alaska. These studies applied a combination of qualitative reasoning and analysis of quantitative socioeconomic variables, such as number of farms established and timber harvest rates, to describe the adaptive cycle. Studies that attempt to quantitatively assess the connectedness and the potential properties as descriptors of specific phase transitions in social-ecological systems, however, remain rare. Two studies explicitly focused on operationalizing the two properties when exploring transformations in social-ecological systems. In the first study, which used Zimbabwe and Australia as case areas, Abel et al. (2006) argued that capital (e.g., human capital and financial capital) captures both potential and connectedness; therefore, the authors described the potential and connectedness in terms of five different capitals. In contrast, in the second study, Nkhata et al. (2008) distinguished between the dimensions of potential and connectedness. They employed trust and commitment as proxies for potential, while they defined connectedness as the degree to which actors in social relationships are linked. Daedlow et al. (2011) also developed indicators to differentiate potential and connectedness, but they researched a purely social system: the East German recreational fisheries governance. All three studies concluded that it has remained a challenge to distinguish and measure the properties of potential and connectedness when applying the adaptive cycle. This may explain why research with an explicit focus on these properties has been rare.

\section{STUDY AREA}

The study was carried out in a small village (Yomboli) with 1040 inhabitants in the Oudalan province of northern Burkina Faso (Fig. 2). Two ethnic groups currently inhabit Yomboli: Fulbe Bambabe is by far the most important with a total of 124 households versus four Bella households. Hence, from an ethnic perspective, Yomboli is remarkably homogenous compared to many other villages in Oudalan. Agricultural and pastoral production are the main sources of sustenance for the population, and the land use system can briefly be characterized as a combination of cultivated fields and pastures. The main crops are pearl millet and sorghum, while cowpeas are grown to a lesser extent. Cropping activities and pastoralism are traditionally integrated, with the most important links being income, feed, and manure. The use of livestock manure enhances soil fertility, and crop residues provide feed for livestock during the dry season (Claude et al. 1991, Reenberg et al. 1998). In the rainy season, livestock graze on village pastures near the mare of Yomboli. To justify our choice of indicators for the potential and connectedness dimension, observed strategies leading to resource accumulation and internal connections in Yomboli are discussed in Study Area: Strategies of resource accumulation and Internal connections and village groups. Resources were defined by villagers as livestock, food, fodder, and money earned during migration. Income from livestock sale was not interpreted as a resource due to the serious loss attached to livestock sale by villagers. 
Fig. 2. Map of Burkina Faso showing the location of Yomboli.

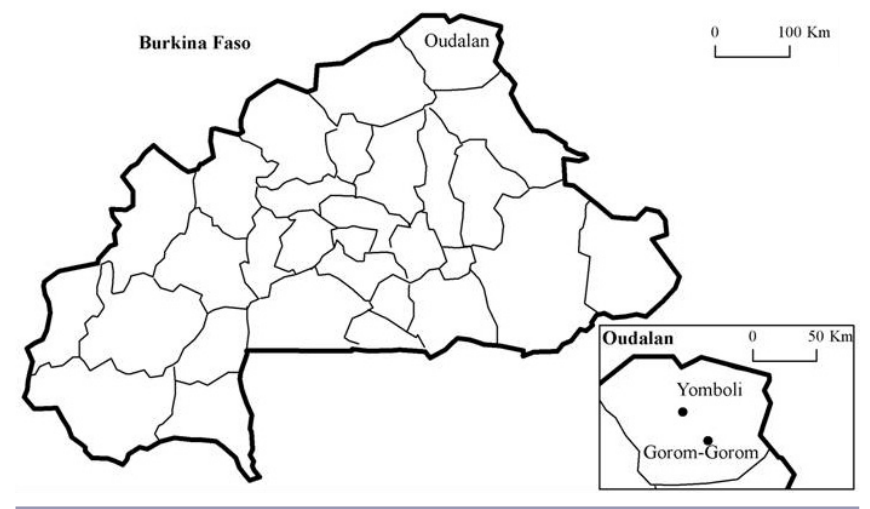

\section{Strategies of resource accumulation}

The Sahelian strategies are in general influenced by a wide range of driving forces operating at different spatial scales, with high variability in annual precipitation being a major challenge together with globalization and population pressure (Dietz et al. 2004). Even in the rainiest years, the harvest meets only five months (on average) of the households' food requirements in Yomboli, while it covers between two and three months in drier years. Fodder resources for livestock are rarely sufficient. Villagers respond to these low outcomes by diversifying their strategies in both rainy and dry years. The fodder deficit is addressed by transhumance and fodder purchase, while the strategies that seek to cover the food requirements can largely be divided into two categories: onfarm and off-farm strategies. The on-farm strategies include expanding the field acreage and intensifying cultivation on existing fields. Expansion is the most widespread strategy because the possibilities of intensification are very limited due to the large labor inputs to applying manure and insufficient economic responses to applying mineral fertilizers. The offfarm strategies that provide money for food purchase include engagement in circular migration, working for development projects, and selling livestock.

When relating these strategies to resource accumulation, there is general agreement among villagers that circular migration always implies increasing resources to the household. Villagers gain "something" by migrating because a proportion of the money earned during migration is used for goods other than food, such as clothes, telephones, and livestock. Like migration, the buying of livestock represents an accumulation of resources. In contrast, the sale of livestock is explained as a serious loss of resources among villagers. They argue that food purchase is the only motivation behind livestock selling because the selling is regarded as "the very last opportunity before eating grass".
It is more complicated to relate expanding and contracting cultivated fields to resource accumulation. On the one hand, villagers explain that in harsh times, fields may be expanded because no young men in the household are able to migrate, for example, due to illness. Due to the lack of income from migration, the household may choose to expand the cultivated area in order to increase food production. This is most often done by including children in the agricultural labor force. Expanding fields is, in this perspective, interpreted as a loss of resources. On the other hand, field expansion may also represent an accumulation of resources. In times of adequate labor or during expectations of a good harvest, for example, villagers are very keen on expanding their fields. Like expansion, contraction of the cultivated area may both represent an accumulation and a loss of resources. In line with expansion and contraction of cultivated land, villagers consider the practice of transhumance and buying of fodder resources as too complex to relate to resource accumulation. Transhumance is practiced in the dry season, but it is a necessity only in dry years. The incentive to practice transhumance has diminished in recent years because it is associated with difficulties: the traditional destinations are becoming increasingly populated and cultivated, which restricts access to water holes and grazing areas (see also Nielsen and Reenberg 2010a). Transhumance thus represents resource loss due to the difficulties incurred. On the other hand, villagers acknowledge that engaging in transhumance implies accumulation of fodder resources. A similar argument is used in relation to the purchase of fodder resources.

\section{Internal connections and village groups}

There has been a long history of village group formations in Burkina Faso, dating back to French colonial rule (Atampugre 1997). The motive for creating groups is most often to promote food security and general development. Since the major drought in the early 1970s, development projects have also constituted a central component in rural communities in the northern Sahel (Nielsen et al. 2011). Frequently, the projects entail configuration of one or more groups within the village. These groups can be of a social disposition, a work-related group, or a group that has some responsibilities in relation to the project. A well-organized village is claimed to be a main criterion for being perceived as a "good" village by, for example, development project staff, and is thus a prerequisite for both attracting projects (and thus more groups) and ensuring that the projects continue after they officially finish. Moreover, social capital and knowledge transfer are often strengthened (Reij et al. 2009) in the process of group formations, and the groups have been claimed to be extremely good at taking "advantage of opportunities in their external environment" (Atampugre 1997). Hence, it can be argued that the presence of groups contributes to controlling the influences of potential external perturbations such as price fluctuations or limited possibilities of making money at the migration destination, for example. 


\section{METHODS}

In order to quantitatively assess the four phases of the adaptive cycle in the case village in Sahel, Yomboli, data were collected during fieldwork carried out in February and March 2010 and between October and December 2010. The data collection served two main aims:

1. the identification of suitable indicators of potential and connectedness

2. the quantitative measurement of changes in these indicators over the past 35 years

The time frame of 35 years for assessment was chosen because the severe droughts in the early 1970s can be characterized as an era of change, and thus represent the start of a distinct temporal period.

\section{Identifying indicators of potential and connectedness}

The identification of indicators was based on participant observation, focus group interviews, and semi-structured interviews. Participant observation was chosen as a first step to gain insight into the daily activities of villagers. The basic insight obtained through participant observation was further explored in semi-structured interviews and focus group interviews with villagers. Thirty-two semi-structured interviews and 10 focus group interviews (with 7-10 persons in each) were conducted. The respondents were stratified according to gender, age, and socioeconomic status, thereby covering main differentiations within the village. All respondents belonged to the ethnic group Fulbe Bambabe. Fifteen villagers were participating both in the focus group interviews and the semi-structured interviews. The semistructured interviews and the focus group interviews served to identify indicators for potential and connectedness, as well as to quantify the connectedness dimension. The quantification of the potential dimension rested on questionnaire-interviews.

In the quest to identify indicators for potential and connectedness, we used the definitions provided by Holling and Gunderson (2002). They defined the potential dimension as the accumulation of resources. Accordingly, we measured this dimension on the basis of the range of strategies in Yomboli that lead to resource accumulation within the household. During the interviews, it became clear, however, that distinguishing strategies that lead to an accumulation of resources from strategies that lead to a loss of resources is not straightforward because some strategies may imply both accumulation and loss of resources. The analysis of the potential dimension was thus confined to two strategies that lead unambiguously to an accumulation of resources, circular migration and buying livestock, and one strategy that leads to a loss of resources, selling livestock. Strategies that may lead to both accumulation and loss of resources were excluded from the analysis (Table 1).
Table 1. Strategies that increase and decrease the accumulation of resources in Yomboli, northern Burkina Faso. The table is based on participant observation, focus group interviews, and semi-structured interviews carried out in Yomboli.

\begin{tabular}{|c|c|c|}
\hline & $\begin{array}{l}\text { Strategies that } \\
\text { increase potential/ } \\
\text { accumulation of } \\
\text { resources }\end{array}$ & $\begin{array}{l}\text { Strategies that } \\
\text { decrease potential/ } \\
\text { accumulation of } \\
\text { resources }\end{array}$ \\
\hline $\begin{array}{l}\text { Strategies not } \\
\text { included in the } \\
\text { analysis due to the } \\
\text { possibility of } \\
\text { representing both } \\
\text { increasing and } \\
\text { decreasing } \\
\text { accumulation }\end{array}$ & $\begin{array}{l}\text { Field expansion } \\
\text { Contraction of } \\
\text { cultivated area } \\
\text { Transhumance } \\
\text { Buying fodder }\end{array}$ & $\begin{array}{l}\text { Field expansion } \\
\text { Contraction of } \\
\text { cultivated area } \\
\text { Transhumance } \\
\text { Buying fodder }\end{array}$ \\
\hline $\begin{array}{l}\text { Strategies included } \\
\text { in the analysis }\end{array}$ & $\begin{array}{l}\text { Buying livestock } \\
\text { Circular migration }\end{array}$ & Selling livestock \\
\hline
\end{tabular}

It should be noted that the use of few indicators may be critiqued on the basis that what is measured addresses only these limited dimensions of the system, and it is likely that different conclusions can be reached with a different set of indicators. The use of indicators may also be critiqued on the basis that what they measure is often guided more by what can be measured than by what should be measured (McCool 2004). We have tried to tackle these challenges by taking a point of departure in the definitions given by Holling and Gunderson (2002) and by carrying out targeted fieldwork in order to choose suitable indicators.

The definitions given by Holling and Gunderson (2002) were likewise used to delimit the connectedness dimension. They defined the connectedness dimension as reflecting the strength of internal connections that regulate the influences between inside processes and external perturbations. We used the presence of village groups formed either by development projects or solely by villagers as a suitable indicator of connectedness. Hence, externally driven as well as internally driven group formations were included. When looking at the internal forms of cooperation, the focus was on groups set up across households, such as women's associations. Groups formed within the household were not included. The number of groups as an indicator of connectedness did not address group performance, which may also be an important aspect of connectedness in the system. Nevertheless, it may be argued that it is indirectly addressed because groups are likely to be dissolved if they do not function.

\section{Quantitative measures of changes in indicators}

The quantitative assessment of indicators for potential was based on focus group interviews and a questionnaire survey. 
The aim of the focus groups was to assess whether the villagers' perceptions of rainy and dry years over the past 35 years were consistent with a rainfall data set from the meteorological station in Gorom-Gorom. The group was first asked to agree on making a list of rainy years and dry years over the past 35 years. Second, precipitation data from 1975 and onwards were presented to the group, and this data set was then compared with the list of perceived rainy and dry years. Where the list was in accordance with the data set, the year was classified as rainy or dry. This research design was chosen due to recall errors among the villagers. Thus, it was obviously not possible to ask the respondents in the questionnaire survey about changes in the indicators for potential (strategies) each year over the past 35 years (Beckett et al. 2001). Because the villagers, in general, remember the past by referring to rainfall instead of actual calendar years, the list made during the focus groups was used as a point of departure for the questionnaire survey.

The quantitative questionnaire survey was conducted with 43 out of a total of 128 heads of households to provide data that could be used to quantify the selected indicators of system potential. Heads of households were the target group because the resource accumulation relates to the household unit and not individual resource accumulation. The survey was conducted with only elderly men in order to have respondents who had recall over the past 35 years. Seven of the heads of households also participated in the focus group interviews and the semi-structured interviews. In the questionnaire survey, respondents were asked to describe their present strategies and changes in strategies (if any) over the past 35 years. This was done by first asking them to describe the main strategies, and then presenting the seven behaviour changes identified during the focus group interviews and semi-structured interviews. The section that presented the seven behaviour changes was structured as simple yes/no questions. At the conclusion of the questionnaires, the respondents were asked to describe their current strategies in a rainy year and in a dry year, and the changes in strategies (if any) over the past 35 years. While the respondents often indicated memory lapse during the question concerning general changes in strategies, they seemed more reflective and confident when asked to describe changes in "dry year strategies" and "rainy year strategies". The reported strategies in respectively rainy and dry years over the past 35 years (adjusted for general changes in strategies indicated in the first section of the questionnaire) were then linked with the rainfall data set generated during the focus group interviews. This was done in order to construct a historical line of changes in the strategies of villagers. Due to the recall errors in "normal" years, only dry years and rainy years were included in the historical line.

As a supplementary data source, the questionnaires were compared with semi-structured interviews and questionnaires from an earlier survey conducted in 1995 in the same village
(Reenberg et al. 1998). However, only 19 of the respondents were also interviewed in 1995. Nonetheless, this step permitted us to control for inconsistencies in the reported changes.

In order to generate quantitative indicators of connectedness, five semi-structured interviews were conducted with staff from both present and former development projects in Yomboli. The interviews were conducted when staff members visited Yomboli but also the neighboring communities of Oursi and Gorom-Gorom, where most organizations have office facilities.

\section{Data analysis}

The collected data from the 43 questionnaires concerning potential were used to calculate the degree of resource accumulation for each year included in the historical line. First, the two strategies that lead to the accumulation of resources were pooled. Second, we calculated the relative frequency of villagers who embraced an accumulation strategy while at the same time not employing a strategy that led to loss of resources. These calculations were performed for each year included in the historical timeline. The formula employed was as follows:

Relative frequency $=([\mathrm{A} \cup \mathrm{B}] \cap \mathrm{C}) / 43$

where A is the surveyed households who bought livestock, B is the surveyed households who migrated, and $\mathrm{C}$ is the surveyed households who did not sell livestock. The calculated relative frequencies are given in Appendix 1. When plotting the calculated levels of potential in 1975-2010, a scale from -1 to 1 was used. No change in resource accumulation was represented by 0 . A relative frequency of 0 was represented by -1 because 0 indicates that all villagers lost resources. A frequency of 100 was represented by 1 , indicating that all villagers accumulated resources. Calculated frequencies less than 0.5 were interpreted as an overall loss of resources in the village, as more villagers lost resources than accumulated resources.

Regarding the connectedness dimension, the number of village groups in each year during the period 1975-2010 was recorded. The characteristic of the village groups, in terms of their contribution to controlling influence from external perturbations, supported our decision to use the presence of groups as an indicator of internal connections, just as Holling and Gunderson include the control of external perturbations in their definition of connectedness.

Having plotted the calculated levels of potential and connectedness in 1975-2010, we compared these observed levels with levels of connectedness and potential in the adaptive cycle, as predicted by Holling and Gunderson (2002). The theoretically assumed combinations of low and high levels of connectedness and potential in the different phases of the adaptive cycle are shown in Table 2. 
Table 2. Generalized levels of potential and connectedness in the four phases of the adaptive cycle, and observed time period with these theoretically assumed combinations of low and high levels of potential and connectedness in the case area.

\begin{tabular}{lcccc}
\hline \hline & $\begin{array}{c}\text { Predictions from the adaptive } \\
\text { cycle heuristic }\end{array}$ & $\begin{array}{c}\text { Observed period with the } \\
\text { theoretically assumed } \\
\text { combinations of low and } \\
\text { high levels of potential } \\
\text { and connectedness }\end{array}$ \\
\cline { 2 - 3 } Phase & Potential & Connectedness & Time period \\
\hline Release & Low & High & $1975-1989$ \\
Reorganization & High & Low & $1990-1994 / 95$ \\
Exploitation & Low & Low & $1994 / 95-1997$ \\
Conservation & High & High & $1998-2003$ \\
Release 2 & Low & High & 2004-Today \\
\hline
\end{tabular}

\section{TRYING OUT THE ADAPTIVE CYCLE}

Observed levels of potential and connectedness in Yomboli during the period 1975-2010 are shown in Fig. 3. In the following section we consider the observed trends in these two dimensions in more detail.

Fig. 3. Levels of potential and connectedness in the case area. The potential was assessed as frequencies of main strategies leading to accumulation of resources, while the connectedness was represented by number of village groups.
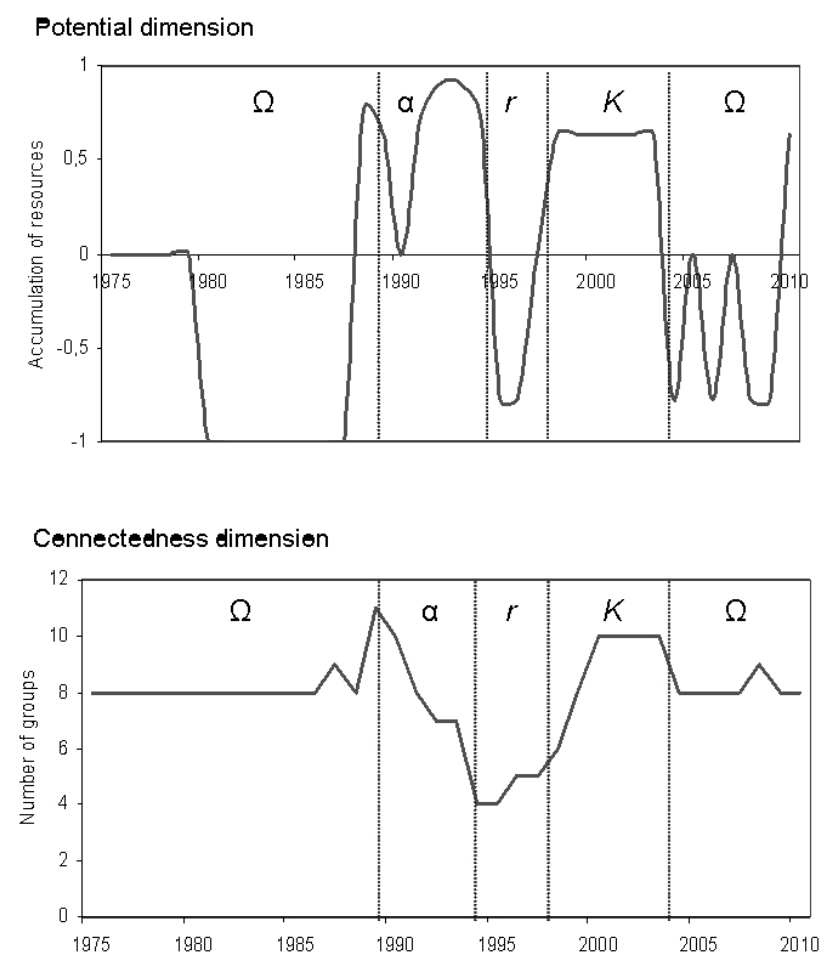

\section{A release phase, 1975-1989}

A potential level of 0 followed by a decline to a low of -1 was observed from 1975 until 1988. This loss of resources in the 1980s can be traced back to the severe droughts in the 1970s before the starting point of the analysis. Many of the elderly villagers lost their livestock during this first sequence of droughts in the 1970s. The interviewees emphasized that they should have chosen to sell the livestock instead of holding onto the cattle as long as possible, but holding onto the cattle was the preferred strategy at that time because the herd was considered to be insurance for the household against particularly bad times. With the severe losses of the 1970s in mind, villagers were reluctant to hold onto their cattle and were more eager to sell when another drought hit again in the 1980s. Villagers were unable to accumulate resources because none of the respondents bought livestock and only $15 \%$ migrated. More importantly, capital in the form of livestock was released. Nevertheless, it should be noted that high livestock mortality rates were experienced during both droughts in Burkina Faso (Food and Agricultural Organization 2010).

In contrast, the observed level of connectedness was high during the 1970s and 1980s. This was a consequence of many group formations with the aim of promoting food security both during and in the aftermath of the severe droughts (Atampugre 1997).

\section{A reorganization phase, 1990-1994/1995}

The observed potential increased substantially from 1989, and an accumulation of resources took place until 1994. The recovery in 1989 was likely enabled by the creation of a cereal bank, which provided the villagers with millet on credit or at highly subsidized prices. Villagers were not forced to sell livestock in order to get food, but the level of migration increased because some kind of income was a requisite for food purchase. Furthermore, the villagers invested a larger proportion of the money earned during migration in livestock. However, three years after its establishment, the cereal bank was close to going bankrupt mainly due to the possibility of getting grain on credit. Consequently, the bank decided to provide only millet at subsidized prices, and villagers were yet again forced to sell livestock in times of food shortage. This may explain the observed decline in the potential of 1993.

The observed level of connectedness was low and decreased during the period. Village groups formed through the joint initiative of extension agents and villagers during the construction of the cereal bank were dissolved shortly after the termination of credit options. According to villagers, "there is no need to be part of a group, when the possibility of getting grain on credit is eliminated".

An exploitation phase, 1994/1995-1999/2000

Low levels of both potential and connectedness were observed in 1995-1997, mainly due to the very dry conditions of 1995- 
1996. The low in potential reflects the fact that $72 \%$ of the respondents remembered selling animals during these years. The high engagement in livestock sale was related to the very clear memory of the enormous losses of the 1970s and 1980s. Moreover, the level of circular migration declined during these dry years because many young men were forced to go on transhumance in order to find pasture and water for the animals. This drought sequence lasted only two years, however, and the accumulation of resources recommenced shortly thereafter. Regarding livestock sale, it must be noted that the fraction of villagers who sold livestock in 1998, for example, which was characterized as a very good year, was $14 \%$. This is because cash is needed to purchase food even in very good years, thus indicating that the sale of livestock should not be linked to droughts only.

The connectedness increased slightly during the period, but the level may still be considered as low. The low level was caused by the dissolution of many village groups throughout the previous period, as already explained. The small increase was triggered by the very dry conditions of 1995-1996, which attracted development projects.

\section{A possible conservation phase, 1999/2000-2004?}

Both potential and connectedness seem to have stabilized at a high level from about 1999 until 2004. The high potential level followed a sequence of good years, while the high level of connectedness was caused by the continued arrival of development projects triggered by the dry period in 19951996.

\section{A second release phase, 2004-?}

A sudden drop in potential was initiated by very dry conditions in 2004. This came after a series of high rainfall years which enabled villagers to rebuild the herds and deal with the dry conditions by selling cattle. Of the 43 interviewed households, $72 \%$ sold cattle in 2004 . None of the villagers bought livestock in 2004, while, for example, $51 \%$ bought cattle in 2003 . The migration level was, however, higher in 2004 than in 2003, but because the income from migration did not cover the food expenses, villagers were forced to sell livestock. This change in strategies implies a decline in the potential dimension and a loss of resources, but the level never reached the low observed during the droughts of the 1980s. Between 2009 and 2010, the potential started to increase with a substantial drop in the fraction of villagers selling livestock. Moreover, villagers bought livestock again.

Whereas connectedness was lower than in the previous period, the level may still be characterized as high. The dissolution of groups that took place from 2003 was explained as being due to the sequence of good years and thereby decreasing incentive to be member of a group. In 2008, the number of groups increased slightly, as Alliance Technique pour l'Assistance au Développement (ATAD) began to intervene in Yomboli. One of the objectives was to strengthen group activities because groups are assumed to increase the capacity of successfully carrying out the different components of ATAD - e.g., women's gardening, livestock fattening. However, another group was dissolved the following year.

\section{Comparison of observed and hypothesized levels of potential and connectedness}

When the observed levels were compared with the theoretically assumed combinations of low and high levels of connectedness and potential in the different phases of the adaptive cycle (Table 2), the history of Yomboli could be described as one iteration of the adaptive cycle occurring over the 30 years between 1975 and 2004 followed by the commencement of a second iteration. Five distinct phases were identified in total, which can potentially be construed as (1) a release phase $(\Omega)$, occurring during the major drought in the 1980s; (2) a reorganization phase $(\alpha)$ between 1989 and 1995; (3) an exploitation phase (r), occurring until about 1999/2000; (4) a very short conservation phase (K) until 2004; and (5) a second collapse $(\Omega)$. This second phase of release continued until 2010, but a second reorganization phase may be impending if the slight decline continues. However, one main difference from the theoretical assumptions is ascertained. The adaptive cycle heuristic suggests that systems tend, with exceptions (Walker et al. 2006a), to be in a long stable conservation phase before entering the very rapid release phase. This is not so with Yomboli because the conservation phase is estimated to have taken only about 4-5 years, while the first collapse lasted 14 years and the second collapse has so far endured for 6 years. A pressing question becomes whether Yomboli actually entered a conservation phase in 1999/2000. Another plausible suggestion may be that Yomboli went directly from exploitation to release in 2004, implying that the exploitation phase lasted from 1995 until 2004. An argument for interpreting the period 1999/20002004 as exploitation rather than conservation is that the frequent very dry conditions, which acted on a system that relied on navigating through droughts rather than on constantly accumulating resources, likely prevented a steady conservation phase.

\section{DISCUSSION}

What has the concept of the adaptive cycle contributed to our understanding of the trajectories of change in Yomboli?

The objective of this study was to demarcate distinct phases of the adaptive cycle in the period 1975-2010. From the analysis, we identified that from the droughts in the 1970s and during another sequence of droughts in the 1980s, Yomboli appeared to be in a release phase. This release phase lasted until the construction of a cereal bank drove the village into recovery in 1989. When the bank decided not to allow millet on credit, it triggered an exploitation phase. There is no clear evidence that Yomboli entered a conservation phase after the 
exploitation phase, but a second release phase was triggered by very dry conditions in 2004 .

To return to the prevailing narrative of land use system dynamics, which assumes a vicious circle of expansion and land degradation prompted by population pressure and low rainfall, the current findings support the scattered empirical evidence, which suggests that this unidirectional narrative may not conform to reality. Firstly, we can surmise that the system appears to be recovering after the severe droughts. The recovery has been enabled by external support, which may indicate that access to external resources is a prerequisite for recovery. On the other hand, Abel et al. (2006) concluded in their study of social-ecological systems in Zimbabwe and Australia that recovery can be inhibited or destroyed by excessive external subsidization. According to the adaptive cycle heuristic, this may be explained by the notion of a rigidity trap, in which the system becomes highly connected, rigid, and inflexible (Holling et al. 2002). If a system appears to be in a rigidity trap, sources of novelty are diminished, thereby preventing an adaptive response to shocks. It seems likely that excessive subsidies lead a system directly into such a rigidity trap. The question is whether continuing credit possibilities in the cereal bank in Yomboli would have implied a rigidity trap by squeezing out villagers' tendency to diversify strategies, thereby creating a resilience that hampers transformation from the current stage of the system to a more desirable one (Reenberg 2009, Stafford Smith et al. 2009)

In addition to explicitly adding the perspective of recovery, which is frequently missing from the current understandings of trajectories of change in Sahelian land use systems, the analysis reveals that the drivers of change dominating the unidirectional narrative may not be the most important. The present study suggests that fast changing variables like credit possibilities and sudden very dry conditions rather than slow changing variables like population pressure constitute the main triggers of change in Yomboli. Holling and Gunderson (2002) predicted that slow, large-scale processes dominate the front loop of the adaptive cycle, while fast, small-scale processes operate in the back loop. Because Yomboli may never have entered a conservation phase characterizing the front loop, this may explain why slow variables have not been important drivers of change. In discussing drivers of change, the application of the adaptive cycle enables the exploration of temporal shifts in the impacts of the same driver. We have proposed that the dry conditions in 2004 caused the system to collapse, while the dry years in 1995-1996 did not due to a lower level of connectedness. Despite these findings, it should be noted that the adaptive cycle heuristic, which is not an absolute (Walker and Salt 2006), cannot be expected to explain causes and effects in specific cases. Hence, disciplinary theories and approaches should supplement the heuristic.

\section{Methodological limitations}

In terms of methodological issues, the present study has demonstrated the analytical challenges of identifying and measuring indicators of potential and connectedness in socialecological systems. As already noted, there is a certain degree of subjectivity associated with the selection of suitable indicators. While the challenges related to the construction of suitable indicators are not fully overcome in this study, we have tried to propose a reasonable approximation by taking a point of departure in the definitions given by Holling and Gunderson (2002) and by carrying out targeted fieldwork. Nonetheless, further research is strongly needed to refine and further develop these indicators.

With respect to possible future trajectories of change in Sahelian systems, it must be pinpointed that although intrinsic cyclicity is a key concept in the heuristic, and despite the evidence of it in many systems, the adaptive cycle is not predictive (Holling and Gunderson 2002). Abel et al. (2006) noted that systems do not necessarily move sequentially between the four phases because large external perturbations can disturb the cyclicity. They argued that the finer the spatial scale of the system, the more susceptible it is to external perturbations and the less likely it is to show cyclicity. Hence, it is not surprising that the observations from Yomboli, which concern a village-scale system, may not support the suggestion of four sequential phases.

Finally, it is important to note that the results are based on findings from Fulbe Bambabe households with an elderly head of household. The demarcated adaptive cycle appears to be uniform for this group. It may be possible that the main dynamics will vary if the analysis is done at the individual level or if one differentiates between old or young, for example. However, the family and household structure in the village builds on the traditional leadership of elderly men. Hence, main household strategies are determined by the senior males.

\section{CONCLUSIONS AND POLICY IMPLICATIONS}

Through the application of the adaptive cycle heuristic, the current study suggests that the picture of a unidirectional process of land degradation and system collapse in Sahelian agro-pastoral systems is a simplification of more complex realities. The empirical findings of this study show far more nuanced processes of change, which include system recovery. In relation to policy interventions, it may be of importance that a high level of connectedness was found during the severe droughts and was followed by a decline in the beginning of the 1990s. The high connectedness was caused mainly by excessive external subsidies. But high connectedness is proposed to constrain system recovery because it may lead the system into a rigidity trap. If this holds true, excessive external subsidies during the droughts may not have been the most suitable way of facilitating recovery and making way for long- 
term sustainable development options (Stafford Smith et al. 2009). Rather, after a system collapse, investments should focus on strategies that lead to an accumulation of resources because this type of intervention is more likely to enable recovery. In this perspective, another question arises as to when one should intervene in the cycle in order to generate the best possible outcome. Cocks (2003) argued that reorganization and recovery should be seen as a "window of opportunity", meaning that the system acts within a diversity of opportunities rather than a diversity of constraints. Both the policy discourse and new research will undoubtedly have to acknowledge such recognitions of recovery and opportunities as this may contribute to a more comprehensive understanding of trajectories of change in Sahelian systems.

Responses to this article can be read online at: http://www.ecologyandsociety.org/vol17/iss 1/art14/ responses/

\section{Acknowledgments:}

The field research was funded by a grant from the DANIDAFFU, 09-001KU, and contributes to the European Research Council project Waterworlds. The study is part of the project A Region Wide Assessment of Land System Resilience and Climate Robustness in the Agricultural Frontline of Sahel (LASYRE). Detailed information on scientific coordination and funding is available on the LASYRE website: http:// www.lasyre.dk. We thank the villagers of Yomboli for spending their days with us, willingly sharing their knowledge on local agricultural and pastoral strategies. Helpful comments given by two anonymous reviewers are gratefully acknowledged.

\section{LITERATURE CITED}

Abel, N., D. H. Cumming, and J. M. Anderies. 2006. Collapse and reorganization in social-ecological systems: questions, some ideas, and policy implications. Ecology and Society 11 (1): 17. [online] URL: http://www.ecologyandsociety.org/vol11/ iss1/art17/

Alcorn, J. B., J. Bamba, and S. N. I. R. A. G. Masiun. 2003. Keeping ecological resilience afloat in cross-scale turbulence: an indigenous social movement navigates change in Indonesia. Pages 299-327 in F. Berkes, J. Colding, and C. Folke, editors. Navigating social-ecological systems: building resilience for complexity and change. Cambridge University Press, Cambridge, UK. http://dx.doi.org/10.1017/CBO97805115419 $\underline{57.018}$

Allison, H. E., and R. J. Hobbs. 2004. Resilience, adaptive capacity, and the "Lock-in trap" of the Western Australian agricultural region. Ecology and Society 9(1): 3. [online] URL: http://www.ecologyandsociety.org/vol9/iss1/art3/
Atampugre, N. 1997. Aid, NGOs and grassroots development: northern Burkina Faso. Review of African Political Economy 24: 57-73. http://dx.doi.org/10.1080/03056249708704238

Beckett, M., J. DaVanzo, N. Sastry, C. Panis, and C. Peterson. 2001. The quality of retrospective data-an examination of long-term recall in a developing country. Journal of Human Resources 36: 593-625.

Beier, C. M., A. L. Lovecraft, and F. S. Chapin. 2009. Growth and collapse of a resource system: an adaptive cycle of change in public lands governance and forest management in Alaska. Ecology and Society 14(2): 5. [online] URL: http://www.ecol ogyandsociety.org/vol14/iss2/art5/

Carpenter, S. R., C. Folke, M. Scheffer, and F. Westley. 2009. Resilience: accounting for the noncomputable. Ecology and Society 14(1): 13. [online] URL: http://www.ecologyandsociety. org/vol14/iss1/art13/

Claude, J., M. Grouzis, P. Milleville, R. Fauck, P. Chevallier, M. Langlois, F. Joly, P. Dewolf, M. Sicot, and J. Collinet. 1991. Un espace Sahelien: la mare d'Oursi, Burkina Faso. ORSTOM, Paris, France.

Cocks, K. D. 2003. Deep futures: our prospects for survival. University of New South Wales Press, Sydney, Australia.

Daedlow, K., V. Beckmann, and R. Arlinghaus. 2011. Assessing an adaptive cycle in a social system under external pressure to change: the importance of intergroup relations in recreational fisheries governance. Ecology and Society 16(2): 3. [online] URL:http://www.ecologyandsociety.org/vol16/iss2/ $\underline{\operatorname{art} 3 /}$

Dietz, A. J., R. Ruben, and A. Verhagen. 2004. The impact of climate change on drylands: with a focus on West Africa. Springer. http://dx.doi.org/http://dx.doi.org/10.1007/1-4020-2158-5

Folke, C. 2006. Resilience: the emergence of a perspective for social-ecological systems analyses. Global Environmental Change-Human and Policy Dimensions 16: 253-267. http://d x.doi.org/10.1016/j.gloenvcha.2006.04.002

Food and Agricultural Organization. 2010. FAOStatcomputerized information series statistics. Food and Agricultural Organization of the United Nations, Rome, Italy. [online] URL: http://faostat.fao.org/site/375/default.aspx

Gunderson, L., and C. Folke. 2005. Resilience-now more than ever. Ecology and Society 10(2): 22. [online] URL: http ://www.ecologyandsociety.org/vol10/iss2/art22/

Gunderson, L. H., and C. S. Holling, editors. 2002. Panarchy: understanding transformations in human and natural systems. Island Press, Washington, D.C., USA. 
Holling, C. S. 2001. Understanding the complexity of economic, ecological, and social systems. Ecosystems 4: 390405. http://dx.doi.org/10.1007/s10021-001-0101-5

Holling, C. S., and L. Gunderson. 2002. Resilience and adaptive cycles. Pages 25-62 in L. Gunderson and C. S. Holling, editors. Panarchy. Understanding transformations in human and natural systems. Island Press, Washington, D.C., USA.

Holling, C. S., L. Gunderson, and G. D. Peterson. 2002. Sustainability and panarchies. Pages 63-102 in L. Gunderson and C. S. Holling, editors. Panarchy. Understanding transformations in human and natural systems. Island Press, Washington, D.C., USA.

Kinzig, A. P., P. Ryan, M. Etienne, H. Allison, T. Elmqvist, and B. H. Walker. 2006. Resilience and regime shifts: assessing cascading effects. Ecology and Society 11(1): 20. [online] URL: http://www.ecologyandsociety.org/vol11/iss1/ art20/

McCool, S. F., and G. H. Starkey. 2004. Indicators of sustainability: challenges and opportunities at the interface of science and policy. Environmental Management 33: 294-305. http://dx.doi.org/10.1007/s00267-003-0084-4

Mortimore, M. 2006. What are the issues? Have the issues changed? Pages 10-18 in Mille Møllegaard, editor. Natural resource management in Sahel-lessons learnt. Proceedings of the 17th Danish Sahel Workshop, 6-7 November 2006. ReNED, Copenhagen, Denmark.

Mortimore, M., and W. M. Adams. 2001. Farmer adaptation, change and 'crisis' in the Sahel. Global Environmental Change-Human and Policy Dimensions 11: 49-57. http://dx. doi.org/10.1016/S0959-3780(00)00044-3

Mortimore, M., and B. Turner. 2005. Does the Sahelian smallholder's management of woodland, farm trees, rangeland support the hypothesis of human-induced desertification? Journal of Arid Environments 63: 567-595. http://dx.doi.org/ http://dx.doi.org/10.1016/j.jaridenv.2005.03.005

Nielsen, J. O., S. D'haen, and A. Reenberg. 2011. Adaptation to climate change as a development project: a case study from northern Burkina Faso. Climate and Development 4(1).

Nielsen, J. O., and A. Reenberg. 2010a. Cultural barriers to climate change adaptation: a case study from northern Burkina Faso. Global Environmental Change-Human and Policy Dimensions 20: 142-152. http://dx.doi.org/http://dx.doi.org/1 $\underline{0.1016 / \text { j.gloenvcha.2009.10.002 }}$

Nielsen, J. O., and A. Reenberg. 2010b. Temporality and the problem with singling out climate as a current driver of change in a small West African village. Journal of Arid Environments 74: 464-474. http://dx.doi.org/http://dx.doi.org/10.1016/j.jari denv.2009.09.019
Nkhata, A. B., C. M. Breen, and W. A. Freimund. 2008. Resilient social relationships and collaboration in the management of social-ecological systems. Ecology and Society 13(1): 2. [online] URL: http://www.ecologyandsociety. org/vol13/iss1/art2/

Reenberg, A. 2009. Embedded flexibility in coupled humanenvironmental systems in the Sahel: talking about resilience. Pages 132-158 in K. Hastrup, editor. The question of resilience. Social response to climate change. The Royal Danish Academy of Sciences and Letters, Copenhagen, Denmark.

Reenberg, A., T. L. Nielsen, and K. Rasmussen. 1998. Field expansion and reallocation in the Sahel-land use pattern dynamics in a fluctuating biophysical and socio-economic environment. Global Environmental Change 8(4): 309-327. http://dx.doi.org/10.1016/S0959-3780(98)00003-X

Reij, C., G. Tappan, and M. Smale. 2009. Agroenvironmental transformation in the Sahel. IFPRI Discussion Paper 00914, November 2009. International Food Policy Research Institute, Washington, D.C., USA.

Seixas, C. S., and F. Berkes. 2003. Dynamics of socialecological changes in a lagoon fishery in southern Brazil. Pages 271-298 in F. Berkes, J. Colding, and C. Folke, editors. Navigating social-ecological systems: building resilience for complexity and change. Cambridge University Press, Cambridge, UK. http://dx.doi.org/10.1017/CBO97805115419 $\underline{57.017}$

Stafford Smith, D. M., N. Abel, B. Walker, and F. S. Chapin. 2009. Drylands: coping with uncertainty, thresholds, and changes in state principles of ecosystem stewardship. Pages 171-195 in F. S. Chapin, G. P. Kofinas, and C. Folke, editors. Principles of ecosystem stewardship. Springer, New York.

Walker, B. H., J. M. Anderies, A. P. Kinzig, and P. Ryan. 2006b. Exploring resilience in social-ecological systems through comparative studies and theory development: introduction to the special issue. Ecology and Society 11(1): 12. [online] URL: http://www.ecologyandsociety.org/vol11/iss1/ $\underline{\operatorname{art} 12 /}$

Walker, B., L. Gunderson, A. Kinzig, C. Folke, S. Carpenter, and L. Schultz. 2006a. A handful of heuristics and some propositions for understanding resilience in social-ecological systems. Ecology and Society 11(1): 13. [online] URL: http:// www.ecologyandsociety.org/vol11/iss1/art13/

Walker, B., and D. Salt. 2006. Resilience thinking. Sustaining ecosystems and people in a changing world. Island Press, Washington, D.C., USA. 
Appendix 1. Number of surveyed households who bought livestock (A), who migrated (B), and who didn't sell livestock (C). The total number of surveyed households is 43 .

\begin{tabular}{lcccccccccccc} 
& $1980-87$ & 1988 & 1989 & 1991 & $1992-93$ & 1994 & $1995-96$ & $1998-2003$ & 2004 & 2006 & $2008-09$ & 2010 \\
\hline $\begin{array}{l}\text { Buying } \\
\text { livestock (A) }\end{array}$ & 3 & 0 & 22 & 22 & 0 & 22 & 0 & 22 & 0 & 0 & 0 & 22 \\
Migration (B) & 15 & 15 & 17 & 17 & 39 & 17 & 14 & 17 & 39 & 39 & 39 & 15 \\
A $\cup$ B & 15 & 15 & 32 & 32 & 39 & 32 & 14 & 32 & 39 & 39 & 39 & 30 \\
$\begin{array}{l}\text { No livestock } \\
\text { sale }(\mathrm{C})\end{array}$ & 0 & 12 & 37 & 43 & 43 & 43 & 12 & 37 & 12 & 12 & 12 & 35 \\
$(\mathrm{~A} \cup \mathrm{B}) \cap(\mathrm{C})$ & 0 & 10 & 27 & 32 & 39 & 32 & 10 & 27 & 10 & 10 & 10 & 27
\end{tabular}

